\title{
New Strategies Against Prostate Cancer - Pt(II)-Based Chemotherapy
}

\author{
C.S. Matos ${ }^{1}$, A.L.M.B. de Carvalho ${ }^{1}$, R.P. Lopes ${ }^{1}$ and M.P.M. Marques, ${ }^{, 1,2}$ \\ ${ }^{1}$ Research Unit "Molecular Physical Chemistry", University of Coimbra - Portugal; ${ }^{2}$ Departament of Life Sciences, Faculty of Sci- \\ ence and Technology, University of Coimbra-Portugal
}

\begin{abstract}
Prostate cancer is the second most common cancer worldwide and the sixth cause of cancer-related death in men. When hormone therapy fails to control tumour growth, castration-resistant prostate cancer (CRPC) occurs and chemotherapy drugs must be administered. Since 2004, docetaxel administration is the standard of care in metastatic CRPC, although it presents severe limitations such as acquired resistance and poor prognosis. An analogue (cabazitaxel) was approved by the FDA in 2010 as a second-line chemotherapeutic agent. Novel immuno- and hormonal therapy agents, as well as tumour vaccines, have been recently developed, but new strategies are still needed for effectively handling this type of neoplasia. Platinum compounds, in particular, have been the object of a growing interest, despite the former belief that they should have modest activity against prostate cancer. Compounds such as carboplatin, oxaliplatin or satraplatin, either alone or in combination, have lately shown promising results. In order to overcome the deleterious side-effects usually associated to these metal-based agents, several approaches have been followed with a view to optimise drug delivery and targeting, some of which showed considerable success in CRPC. Platinum drugs may therefore have an important role in the chemotherapeutic management of human metastatic castration-resistant prostate cancer, mostly in second-line strategies. The present review addresses the most relevant studies on platinum-based antineoplastic agents towards CRPC in the last decade - from first- and second-generation complexes to newly developed compounds.
\end{abstract}

Keywords: Castration-resistant prostate cancer (CRPC), metastasis, chemotherapy, platinum agents, cisplatin, carboplatin, oxaliplatin, picoplatin, satraplatin, single administration, combined administration, targeted delivery.

\section{INTRODUCTION}

Prostate cancer is the second leading cause of male cancerrelated mortality in the western world $[1,2]$. Although outcomes for patients with prostate cancer are best when the disease is diagnosed in the organ-confined state (being then curable), a significant proportion of men (10-20\%) display metastasis at presentation (predominantly to bone) and the currently available treatment options for these cases have a modest prognosis [3]. The established therapy for advanced prostate cancer has been androgen deprivation, either by medical or surgical castration. Nevertheless, a high number of patients progress to an androgen-independent phenotype after about 18 to 36 months (castration-resistant prostate cancer (CRPC)), which is almost inevitably associated with metastasis (mainly to bone tissue) - metastatic castration-resistant prostate cancer (mCRPC) $[4,5]$. Thus, when hormone therapy fails to control tumour growth and an hormone-refractory state emerges, chemotherapy strategies must be applied [6].

In fact, chemotherapy has yielded promising results in metastatic hormone-refractory prostate cancer, with a significant role in the palliation of symptoms. The currently Food and Drug Administration (FDA) approved first-line chemotherapeutic agents for CRPC treatment include mitoxantrone (an anthracycline derivative [7, 8], estramustine (an estrogen derivative), and docetaxel [9] Fig. (b). Even though combinations of these agents were found to induce an encouraging biochemical response in more than $50 \%$ of the patients [10-12], the average duration of response does not exceed 6 months with an overall survival (OS) between 18 and 24 months. Therefore, numerous studies are on-going, with a view to test different therapeutic schemes for achieving an optimal regimen, capable of extending life in patients with metastatic CRPC or high-risk localised disease.

Since 2004 combined administration of docetaxel (tradename Taxotere) and prednisone has been the standard first-line treatment for metastatic CRPC $[9,13,14]$. Additionally, docetaxel/ estramustine combinations were proposed as first-line chemotherapy against advanced prostate cancer and verified to be active, with tolerable side effects [14-17]. Lately, the recently approved (2010) cabazitaxel docetaxel analogue (obtained through hydroxyl

*Address correspondence to this author at the Dep. Life Sciences, Fac. Science and Technology, University of Coimbra, Ap. 3046, 3001-401 Coimbra-Portugal; Tel: +351 239826541; Fax: +351239826541; E-mail: pmc@ci.uc.pt by methoxyl substitution) [18-20], has been used, although both are limited by acquired resistance, with an overall survival not exceeding two years [21].

In view of this short duration of clinical response and of the scarce therapeutic options after taxane failure, other post-docetaxel options have recently been explored: (i) immunotherapy with autologous vaccines - sipuleucel-T (Provenge ${ }^{\mathrm{TM}}$ ), approved in 2010 by FDA for the treatment of asymptomatic or minimally symptomatic mCRPC [22, 23] - and Prostvac (in phase III clinical trials) that has increased the median survival time by 8.5 months [24]; (ii) the highly targeted alpha-pharmaceutical Alpharadin (Radium-223 chloride, phase III trials) [25], and the human monoclonal antibody Denosumab in patients with bone metastasis [26-29]; (iii) or novel hormonal therapy strategies such as the androgen-receptor antagonist Enzalutamide [30-32], and the orally administered androgen inhibitor abiraterone acetate (AA, Zytiga ${ }^{\mathrm{TM}}$ ) [33-35]. According to the highly promising results obtained in phase III clinical trials for abiraterone [36], this is a landmark in prostate cancer treatment. The recent combined administration of abiraterone and cabazitaxel to patients with $\mathrm{mCRPC}$, not responsive to docetaxel treatment, has led to a significant overall survival benefit [37].

The quest for second-line antineoplastic agents that will effectively control mCRPC, either alone or in combination, is therefore a high priority issue in prostate cancer research $[38,39]$. The present review comprises the most relevant developments in this field in the last ten years, regarding the role of platinum-based antineoplastic agents - both $\mathrm{Pt}(\mathrm{II})$ and new generation $\mathrm{Pt}(\mathrm{IV})$ orally available compounds.

\section{PLATINUM-BASED CHEMOTHERAPEUTIC STRATE- GIES}

Since prostate cancer often becomes refractory to hormonal manipulation, alternative strategies must be sought to be used in men whose disease progresses during or after taxane therapy. Cytotoxic metal-based chemotherapy is emerging as an effective form of treatment of this type of advanced (metastatic) prostate cancer (mCRPC) [40-45]. Platinum-based chemotherapeutics, in particular, are among the most widely prescribed drugs in modern oncology (used to treat $c a .50 \%$ of all cancers), either alone or in combination with other systemic compounds and/or radiation therapy. They are known to be active in a wide range of solid tumours, including lung, head and neck, colon, bladder, ovarian and testicular 
cancers, and exert their cytotoxic action through specific interactions with DNA [46, 47]. Three of these compounds are currently approved for clinical use: cisplatin, carboplatin and oxaliplatin Fig. (1). Nevertheless, they are associated to severe side-effects (e.g. ototoxicity, neurotoxicity, nephrotoxicity and myelosuppression) as well as to acquired resistance, and require intravenous administration.

Platinum chemotherapy has, for a long time, been considered inactive against CRPC, but more recent data (since the middle 1990's) has proved otherwise, mainly due to the advent of new drugs and novel methods of response assessment [40, 48]. In fact, cisplatin and second-generation carboplatin have lately been found to yield a moderate response in metastatic CRPC patients [49-51]. Carboplatin, in particular, yielded promising results inducing very high response rates in several combined therapeutic schemes (e.g. with estramustine or taxanes [52, 53]). Furthermore, platinum drugs with altered stable ligands, such as oxaliplatin and new generation platinum agents such as picoplatin and the orally available satraplatin Fig. (1) have distinct therapeutic profiles and display significant anticancer activity in diseases with inherent or acquired resistance to cisplatin, such as prostate cancer [42]. However, as singleagents platinum compounds have displayed a modest activity towards castration-resistant prostate cancer ( $\mathrm{ca} .17 \%$ response rates [54]), while they offer the greatest potential in combined administration $[49,55,56]$. As an example, treatments with picoplatin plus docetaxel [19], carboplatin plus taxanes and estramustine [57], carboplatin plus etoposide in docetaxel-pretreated patients [58], or cisplatin plus prednisone in docetaxel-refractory CRPC patients [59], have showed promising efficacy in phase II trials.

\subsection{Cisplatin}

Since the discovery of cisplatin by Rosenberg, in 1965 [60, 61], and its FDA approval for clinical use in 1978, this square planar Pt(II) complex (cis-(diamminodichloro)platinum(II), tradename Platinol, Fig. a) has become first-line therapy for several human cancer types. Cisplatin damaging effect on DNA is due to shortrange inter- and intrastrand cross-links (mainly at the double-helix purine bases) leading to apoptptic cell death, thus suppressing proliferation [62-64].

Although cisplatin was shown, in the 1980's, to display marginal to modest antitumour activity against CRPC [65-68], improved response assessment methods allowed to redefine this effect. No reports are to be found on its use in sole administration for the treatment of advanced prostate cancer, but several studies are underway regarding combined therapeutic schemes comprising cisplatin, with an encouraging outcome.

A phase II clinical trial combining cisplatin, doxorubicin and etoposide was carried out by Papandreou et al. [69]: patients were treated every 4 weeks with doxorubicin $\left(50 \mathrm{mg} / \mathrm{m}^{2}\right.$ per day as an intravenous infusion), followed by etoposide $\left(120 \mathrm{mg} / \mathrm{m}^{2} \mathrm{per}\right.$ day) and cisplatin $\left(25 \mathrm{mg} / \mathrm{m}^{2}\right.$ per day). However, this led to a very high toxicity that hindered clinical use.

Cisplatin plus docetaxel were tried by Culine and coworkers [70], although the therapeutic results were disappointing, the efficacy having been low and the toxicity too high to allow use in the clinical practice.

Prednisone (a synthetic immunosuppressant corticosteroid, Fig. 2) was also tested in combination chemotherapy with several platinum agents. A clinical phase II trial was performed with cisplatin, at a dosage of $75 \mathrm{mg} / \mathrm{m}^{2}$ every 3 weeks, coupled to prednisone, at $10 \mathrm{mg}$ daily [59], resulting in a prostatic-specific antigen (PSA) reduction of more than $50 \%$ in $20 \%$ of the patients, with a good tolerance profile. Time to progression was 5.6 months, and the average overall survival was 13.8 months.

\subsection{Carboplatin}

Carboplatin (cis-diammine(1,1-cyclobutanedicarboxylato) plati num(II), tradename Paraplatin) is a second-generation Pt(II) compound, that differs from cisplatin by the presence of a bidentate dicarboxylate ligand as its leaving group instead of the more labile cisplatin's chloride ligands [57] Fig. (1). Consequently, this compound displays a significantly lower reactivity and slower DNA binding kinetics [71], although it yields the same DNA adducts. This chelate is substantially more stable than cisplatin, allowing more time for the drug to reach the target molecule [72] and leading to a longer lasting effect - it has a retention half-life of 30 hours, as compared to 1.5-3.6 hours for cisplatin. Moreover, it presents reduced side-effects relative to cisplatin, particularly the elimination of nephrotoxicity, and was shown to be effective in some strains of cancer not susceptible to cisplatin.

In 2006, Castagneto and collaborators reported a study on CRPC patients, that were administered carboplatin at a dose of 150 mg weekly for 3 weeks. From 27 cases, $26.9 \%$ experienced a decline of $\leq 50 \%$ in PSA after therapy allowing to conclude that carboplatin has a definite activity against CRPC, whether it is administered weekly or monthly [73]. Apart from this, there are no reported studies on carboplatin in sole administration towards advanced prostate cancer, but several combination regimens have been investigated.

In a phase II trial using carboplatin plus docetaxel [74], patients were treated with the taxane intravenously at a dose of $60 \mathrm{mg} / \mathrm{m}^{2}$, and with carboplatin at an Area Under the Curve (AUC) 4, every 21 days, in a reasonably well tolerated therapeutic scheme. PSA was found to decrease by more than $50 \%$ in $18 \%$ of the treated patients. The median time to progression was 3 months and the average overall survival time was 12.4 months. This treatment scheme yielded a modest antineoplasic activity, a better response having been obtained in patients pre-treated with docetaxel.

A combination of carboplatin and another taxane, paclitaxel, was investigated by Jeske et al. [75] for the treatment of 25 CRPC patients, paclitaxel having been administered at a dose ranging from 60 to $80 \mathrm{mg} / \mathrm{m}^{2}$ at days 1,8 and 21 , on a 28 -day cycle, plus carboplatin AUC 4-6 at day 1, in an average of 4.5 therapeutic cycles. This combination was well tolerated, with $48 \%$ of the patients achieving over $50 \%$ PSA reduction. Time to disease progression was 3 months and the OS was 10.5 months.

Furthermore, several clinical trials have been performed using etoposide (a topoisomerase II inhibitor often used as an antineoplastic drug [76]) in combination with a platinum agent. One of these, using etoposide at a dose of $80 \mathrm{mg} / \mathrm{m}^{2}$ per day from days 1 to 3 , and carboplatin AUC 5 at day 1, repeated every 3 weeks, led to encouraging results [58]: $9 \%$ of the patients experienced a reduction in their PSA levels of more than $50 \%$, with an average OS of 19 months and no significant side effects.

Triplet therapy schemes, combining estramustine, a taxane and a platinum agent, have also been explored. In a phase II clinical trial involving 56 patients, these were administered paclitaxel at $1-$ hour infusions of $60-100 \mathrm{mg} / \mathrm{m}^{2}$ per week, oral estramustinephosphate at a dose of $10 \mathrm{mg} / \mathrm{Kg}$, and carboplatin at an AUC (representing serum concentration) of $6 \mathrm{mg} / \mathrm{ml}$-min every 4 weeks [77]. This scheme, repeated for 4 therapeutic cycles, induced a significant antitumor activity, with a reduction in PSA levels of over $50 \%$ in $67 \%$ of the treated patients, a time to disease progression of 5.3 months, and an average OS of 19.9 months. A similar treatment regimen was followed by Urakami et al. [55], using a combination of paclitaxel $\left(60-100 \mathrm{mg} / \mathrm{m}^{2}\right.$ per week), estramustine $(10 \mathrm{mg} / \mathrm{Kg}$ per day) and carboplatin (AUC equal to 6) every 4 weeks, with very good results - a PSA level decrease of more than 50\% was achieved in all treated patients, coupled to an overall survival time of 24 months. 

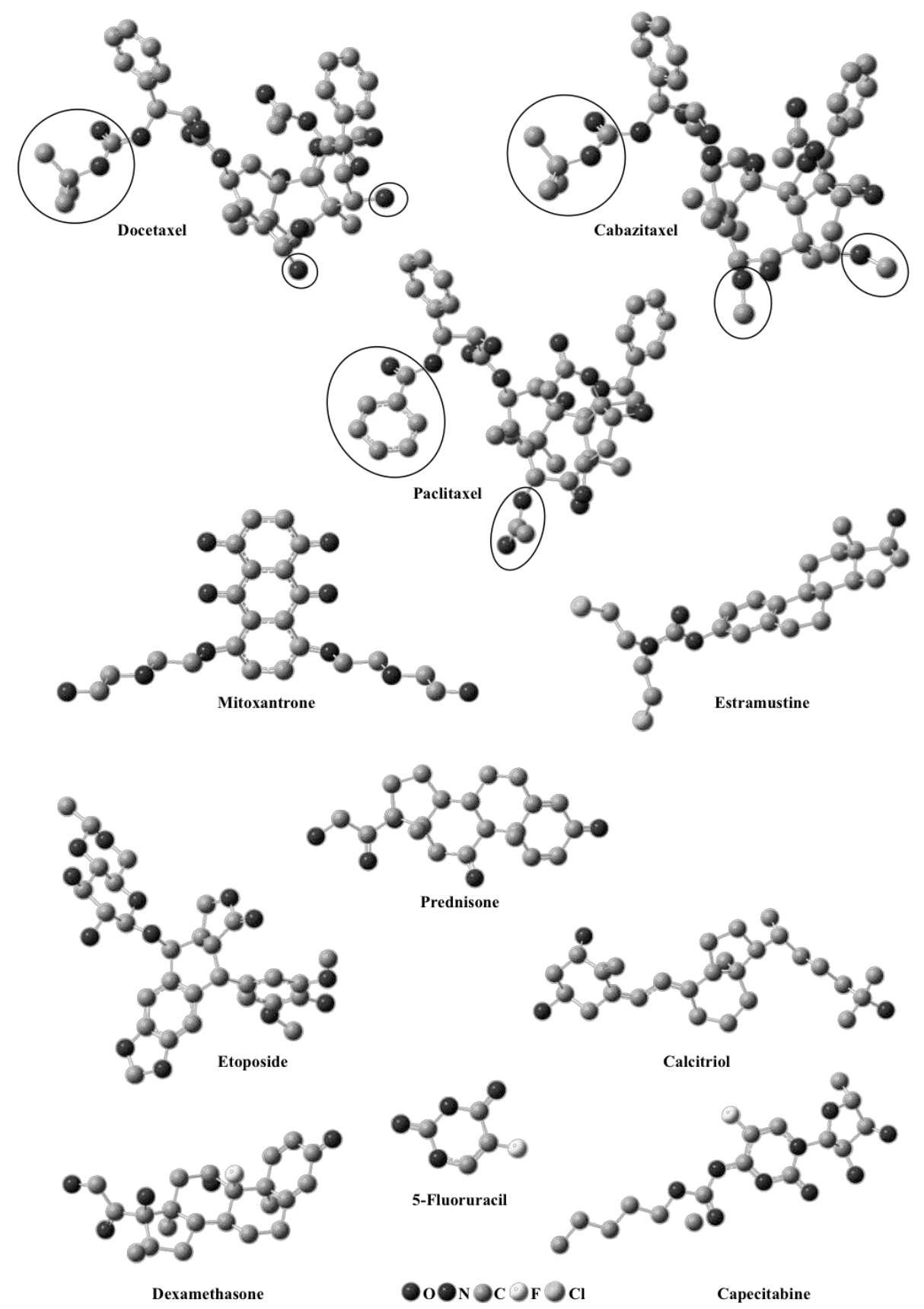

Fig. (1). Structural representation of several platinum anticancer agents. The clinical used drugs are comprised in the shaded square.

(The represented structures correspond to optimised geometries, calculated by the authors using quantum mechanical methods at the Density Functional Theory level).

Oh and coworkers [52] conducted a phase II trial using estramustine, docetaxel and carboplatin, combined with a granulocytecolony-stimulating factor (G-CSF) to minimize neutropenia (usually associated to this type of therapeutic regimen): 34 patients received $240 \mathrm{mg}$ of estramustine 3 times per day for 5 days, 70 $\mathrm{mg} / \mathrm{m}^{2}$ of docetaxel, and carboplatin at a dosage of AUC 5 . A significant clinical activity was achieved, with an acceptable toxicity profile, $68 \%$ of the patients having reduced their PSA levels more than $50 \%$, with an average time to progression of 8.1 months and an OS period of 19 months.

A similar trial was carried out by Solit et al.[56], the patients having received 1-hour infusions of estramustine-phosphate weekly, paclitaxel at a dose of $100 \mathrm{mg} / \mathrm{m}^{2}$ (intravenously) and car- boplatin at AUC 6 every 4 weeks ( 30 minutes infusions). After a 64-week cycle, an average response duration of 5.3 months was achieved, with an OS of 16.6 months. Moreover, administration of oral estramustine was found to lead to an improved activity against bone metastasis.

$\mathrm{Oh}$ and collaborators conducted another clinical trial using a similar therapeutic scheme [53]: 30 patients were treated, in a 28day cycle, with docetaxel (from 20 to $43 \mathrm{mg} / \mathrm{m}^{2}$ on days 2, 9 and 16), estramustine (at $140 \mathrm{mg}$, orally administered, 3 times per day, on days 1-5, 8-12 and 15-19) and carboplatin on day 2 (AUC 5 or 6). This regimen was well tolerated, myelosuppression being the main deleterious side effect. $63 \%$ of the patients achieved a PSA reduction over $50 \%$, and the overall survival time was 14.6 months. 


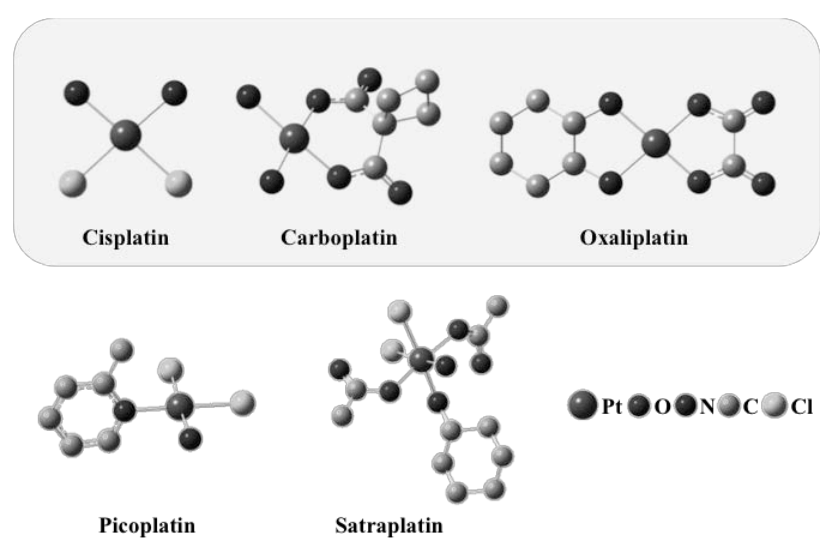

Fig. (2). Structural representation of several chemotherapeutic agents used against CRPC.

(The represented structures correspond to optimised geometries, calculated by the authors using quantum mechanical methods at the Density Functional Theory level).

Kikuno et al., in turn, performed a phase II clinical trial for the following therapeutic scheme [78]: weekly docetaxel at a dose of $30 \mathrm{mg} / \mathrm{m}^{2}$ (administered intravenously), daily estramustinephosphate at $10 \mathrm{mg} / \mathrm{kg}$, and carboplatin AUC 6 on day 1 , in a 4 week cycle. After a total of 6 cycles, the PSA levels were found to decrease by $50 \%$ in $95 \%$ of the patients. The median time to progression was 12.0 months, with an OS of 26.6 months. The toxicity profile was acceptable and the regimen was thus considered to have a significant clinical activity.

A paclitaxel/estramustine/carboplatin regimen was investigated in 84 patients with hormone-refractory prostate cancer, in a 4-week cycle [79]. $18 \%$ of the patients had received previous chemotherapy, $73 \%$ had undergone surgery, and $61 \%$ had received externalbeam radiation therapy. Paclitaxel at $80 \mathrm{mg} / \mathrm{m}^{2}$ and carboplatin AUC 2 were administered intravenously on days 2, 9, and 16, and oral estramustine at $280 \mathrm{mg}, 3$ times daily, was given on days 1-3, 8-10, and $15-17$ for 6 cycles. A PSA decrease rate of $61 \%$ was obtained, with an average survival of 15.3 months. This study allowed to conclude that paclitaxel/estramustine/carboplatin administered in a weekly regimen is highly effective, and quite safe, for the treatment of CRPC.

A different therapeutic scheme was applied by Flaig and coworkers [80], who used a combination of dexamethasone (a synthetic corticosteroid), calcitriol (the hormonally active form of vitamin D) and carboplatin, in a phase II trial: for a 6 week cycle, 34 patients received $1 \mathrm{mg}$ of dexamethasone daily, $0.5 \mathrm{mg}$ of calcitriol in the begining of week 5, and carboplatin AUC 2 for the first 4 weeks. A PSA decrease of over $50 \%$ was verified for $35.4 \%$ of the treated patients, with a time to disease progression of 4.5 months and an OS period of 24.4 months, in a well tolerated regimen.

\subsection{Oxaliplatin}

Oxaliplatin ([(1R,2R)-cyclohexane-1,2-diamine](ethanedioato$O, O^{\prime}$ )platinum(II), tradename Eloxatin) is a $\mathrm{Pt}(\mathrm{II})$ complex comprising a bidentate diaminocyclohexane stable ligand and an oxalate leaving group Fig. (1). Inclusion of the diaminocyclohexane moiety was intended to contribute to a larger cytotoxicity when compared to cisplatin and carboplatin, as well as to avoid cross-resistance with these widely used drugs [81].

In a randomised multicenter phase II trial enrolling 54 patients, the activity of oxaliplatin, either alone (OXA) or in combination with the antimetabolite 5-fluorouracil (OXFU), was evaluated [82].
The patients (with identical characteristics) who received an average of 269 treatment cycles were divided in two groups, OXA (106) and OXFU (163). The oxaliplatin dose-intensity was similar in both: OXA - $43 \mathrm{mg} / \mathrm{m}^{2}$ per week, OXFU $-40 \mathrm{mg} / \mathrm{m}^{2}$ per week. The median time to progression thus obtained was 2.6 months in OXA and 3.4 months in OXFU, with OS values of 11.4 months in the latter against 9.4 months achieved in the OXA group.

Combined administration of oxaliplatin with oral capecitabine (a prodrug, enzymatically converted to 5-fluorouracil in the tumour) was also tested, in a phase II clinical trial [83], on patients unresponsive to first-line docetaxel treatment. $100 \mathrm{mg}$ of oxaliplatin were administered at day 1 , plus $1000 \mathrm{mg}$ of capecitabine on days 1 to 14 , every 21 days. $57 \%$ of the patients showed a PSA reduction of over $50 \%$, with a time to disease progression of 3.6 months and an average overall survival of 6 months. This therapeutic scheme was found to be both tolerable and safe, with a promising antineoplastic activity. Additionally, it was assessed as first-line chemotherapy in advanced prostate cancer patients with an average age of 75 years [83]. Given its ease of administration, it was found to represent a good therapeutic option in the elderly.

The combination of oxaliplatin and docetaxel has showed to have a promising activity in CRPC, with a readily manageable toxicity (mostly hematologic) [84]. Phase III trials with this novel regimen have led to high PSA response rates, long progression free survival (PFS) and OS values. Furthermore, a phase II trial was conducted with the primary objective of evaluating PSA response rates in men who have failed primary chemotherapy [84]: oxaliplatin and docetaxel were administered to patients with metastatic castration-resistant prostate cancer, previously treated with up to two cytotoxic chemotherapy regimens, with positive results and controllable safety.

\subsection{Picoplatin}

Picoplatin (cis-(amminedichloro-2-methylpyridine)platinum(II), AMD473 or ZD0473) is a sterically hindered Pt(II) mixed amine complex, designed to overcome platinum resistance and with a potential for improved safety compared to other platinum agents [85-88]. Since one of the amines is substituted by a methyl pyridine, as compared to cisplatin Fig. (1), glutathione competition occurs through a dissociative thiol substitution reaction instead of an associative one (as for cisplatin). This leads to a slower substitution, therefore unfavouring the glutathione-mediated resistance mechanisms [89].

No studies on picoplatin as a sole chemotherapeutic agent against CRPC are yet to be found in the literature. In turn, its combination with other agents such as taxanes (e.g. docetaxel) and prednisone produced encouraging results.

In a phase II trial, intravenous picoplatin was safely administered every three weeks to patients with CRPC as a first-line therapy at $120 \mathrm{mg} / \mathrm{m}^{2}$ with full doses of docetaxel $\left(75 \mathrm{mg} / \mathrm{m}^{2}\right)$ and prednisone (5 mg, twice a day) [90, 91]. A positive PSA response was verified in $78 \%$ of the tested patients, with an average progression free survival of 7.4 months and an overall survival of 21.4 months.

No neurotoxicity was observed and thrombocytopenia (platelet decrease) was less frequent and less severe when picoplatin was administered in combination with docetaxel, neutropenia (decreased white blood cells) being the most common hematologic adverse event. Hence, the combined administration of picoplatin with full doses of docetaxel and prednisone appears as a promising novel therapeutic scheme for the first-line treatment of men with metastatic castration-resistant prostate cancer.

The favourable results obtained for this experimental Pt(II)drug, specifically developed for the treatment of patients with solid tumours, pave the way for late-stage studies aiming at an anticancer 
activity similar to that of other platinum agents, such as oxaliplatin, coupled to a lower toxicity (e.g. nephro- and neurotoxicity) and the ability to overcome glutathione-mediated resistance.

\subsection{Satraplatin}

Satraplatin (bis-(acetato)amminedichloro (cyclohexylamine) platinum(IV), JM216, tradename Orplatna) is a third-generation platinum compound, structurally similar to cisplatin but comprising two axial acetate groups Fig. (1) responsible for an improved oral bioavailability, that renders satraplatin the first platinum agent to be administered orally [92]. Satraplatin is rapidly metabolised into the corresponding cisplatin analog (cisamminedichloro-(cyclohexy lamine)-platinum (II), JM 118) by removal of the acetate moieties [93], and displays improved properties compared to other platinum agents like cisplatin, carboplatin and oxaliplatin [88, 93-95], namely the potential to overcome platinum resistance [96] and the significantly milder toxicity profile [97]. Additionally, since satraplatin is more hydrophobic than cisplatin or oxaliplatin, it has demonstrated efficacy in cisplatin-resistant tumours. Its main metabolite binds to DNA through intrastrand and interstrand crossing links between adjacent purine bases, leading to cell-cycle arrest at the G2 phase and subsequent induction of apoptosis [98]. Moreover, the lack of cross-resistance of taxane-resistant cells to satraplatin is of particular importance, since docetaxel has become the new standard first-line chemotherapy in the treatment of hormone-refractory prostate cancer patients. Thus, satraplatin is an attractive candidate for clinical application towards CRPC.

Upon oral administration, satraplatin is rapidly absorbed, reaching peak plasma levels within $2 \mathrm{~h}$. After a 5-day administration scheme, at a dose of $100 \mathrm{mg} / \mathrm{m}^{2}$, the drug's half-life is $c a$. 12 hours $[99,100]$. Satraplatin and its metabolites are largely bound to blood constituents and plasma proteins, only a small percentage occurring as free platinum. In small-animal tumour models, a 5-day therapeutic scheme was associated with optimal bioavailability, antitumour activity and tolerability [101].

In preclinical studies, satraplatin displayed a significant cytotoxic effect both against the androgen-sensitive $\mathrm{LNCaP}$ and the androgen-insensitive PC-3 and DU-145 cell lines [92, 102], with concentrations leading to a $50 \%$ inhibition $\left(\mathrm{IC}_{50}\right)$ equal to 10.9 $( \pm 0.6), 1.4( \pm 0.1)$ and $2.8( \pm 0.2) \mu \mathrm{M}$, respectively, following 72 hours of incubation. Hence, satraplatin was shown to inhibit prostate cancer cell proliferation, being active in either androgensensitive and androgen-insensitive cells.

The clinical indication for Orplatna (satraplatin capsules) is treatment of men with androgen-independent prostate cancer that has failed prior chemotherapy. Based on previous results for phase I/II trials on cisplatin and carboplatin, several phase I clinical trials have been performed for satraplatin as a single-agent, with different dosing schedules, from a daily dosing to a weekly administration $[97,99,100,103,104]$. These trials confirmed the recommended dosage as $80-120 \mathrm{mg} / \mathrm{m}^{2}$ per day for five consecutive days, every 45 weeks.

Phase II studies on satraplatin as a first-line treatment for CRPC were also carried out, in order to determine the agent's antitumour activity towards this type of cancer as well as its safety profile. Latif and coworkers [105] used a therapeutic scheme with satraplatin at $120 \mathrm{mg} / \mathrm{m}^{2}$ per day for five days, repeated every three weeks. From the 39 patients tested, 10 were found to achieve a complete or partial PSA response, 14 attained a stable disease, and PSA progression occurred in 8 cases. For 7 patients the PSA response could not be evaluated due to missing values, and treatment was discontinued due to toxicity in 14 other patients. The median OS was assessed as 16.7 months.
A combined therapeutic regimen against CRPC, involving satraplatin and docetaxel, was found to be feasible in a phase I trial, with neutropenia as the main toxicity [106]. Docetaxel was administered intravenously over 1 hour on day 1 , and satraplatin was given orally on days 1 to 5 , in 21-day cycles. The preliminary data gathered so far justifies further evaluation in selected advanced prostate cancer patients.

Satraplatin has also been tested in several combined therapeutic schemes with prednisone [93, 107], having been found to reduce the risk of disease progression by about one-third in patients with advanced prostate cancer, unresponsive to hormone treatment and previous chemotherapeutic strategies. In a randomised multicenter phase III trial enrolling 380 patients [108], the Pt(IV) complex was administered at a dose of $100 \mathrm{mg} / \mathrm{m}^{2}$ per day for 5 days, plus oral prednisone at $10 \mathrm{mg}$ twice a day. As compared with prednisone alone, this combination scheme presented better results, with an average OS of 14.9 months and a PFS of 5.2 months. The antitumoral activity associated with this combined chemotherapy was significant, with a minimal toxicity.

Another clinical trial tested satraplatin administered at 80 $\mathrm{mg} / \mathrm{m}^{2}$ once daily for 5 consecutive days, with cycles repeated every 35 days, coupled to a continuous treatment with low-dosage prednisone (5 mg daily) [109]. This combination regimen showed promising activity particularly against cisplatin-resistant human CRPC tumour lines in phase trials I and II, and is currently under clinical trials as a second-line chemotherapy - phase III trial known as Satraplatin and Prednisone Against Refractory Cancer (SPARC) $[109,110]$.

The pivotal SPARC trial, initiated in 2003, is an international, multicenter, placebo-controlled trial with the primary objective of comparing PFS and OS in patients with advanced (metastatic) CRPC, after failure of first-line chemotherapy: 950 patients were treated with satraplatin $(n=635)$, or with placebo plus prednisone $(n=315)$. The time-to-pain progression, pain response, tumour response and PSA response, as well as the safety of the platinum agent in this setting, are also assessed. The proposed dosing regimen was $80 \mathrm{mg} / \mathrm{m}^{2}$, administered once daily for 5 consecutive days, with cycles repeated every 35 days, and continuous treatment with low-dose prednisone (5 mg twice a day). Overall, satraplatin was well tolerated in the elderly patient population (median age 70 years), which is representative of the overall CRPC population. Up to now, the most common adverse effect associated to this agent is myelosuppression, with neutropenia seen in $21.1 \%$ of patients in the satraplatin-plus-prednisone cohort compared with $0.6 \%$ for prednisone alone.

Nevertheless, satraplatin is not yet licensed in Europe for the treatment of prostate cancer. FDA has recently recommended delaying the drug's approval, until reliable data is available on relevant parameters such as OS, PFS and time to pain progression.

Table 1 comprises the most relevant therapeutic schemes against CRPC including platinum-based compounds, reported in the last decade.

\section{TARGETED DELIVERY STRATEGIES}

Different targeted delivery strategies have lately been developed to increase the effectiveness of anticancer platinum drugs towards advanced prostate cancer and to overcome their systemic toxicity, by enhancing tumour delivery through different targeting approaches [111-113]. These allow to target specific sites with controlled release of the drug over a specific period of time. Polymer coupling, liposome encapsulation or antigen-based schemes are some possible approaches, leading to a simultaneous improvement in efficacy and tolerability. 
Table 1. Main Therapeutic Schemes Including Pt-Agents Used Against CRPC in the Last Decade

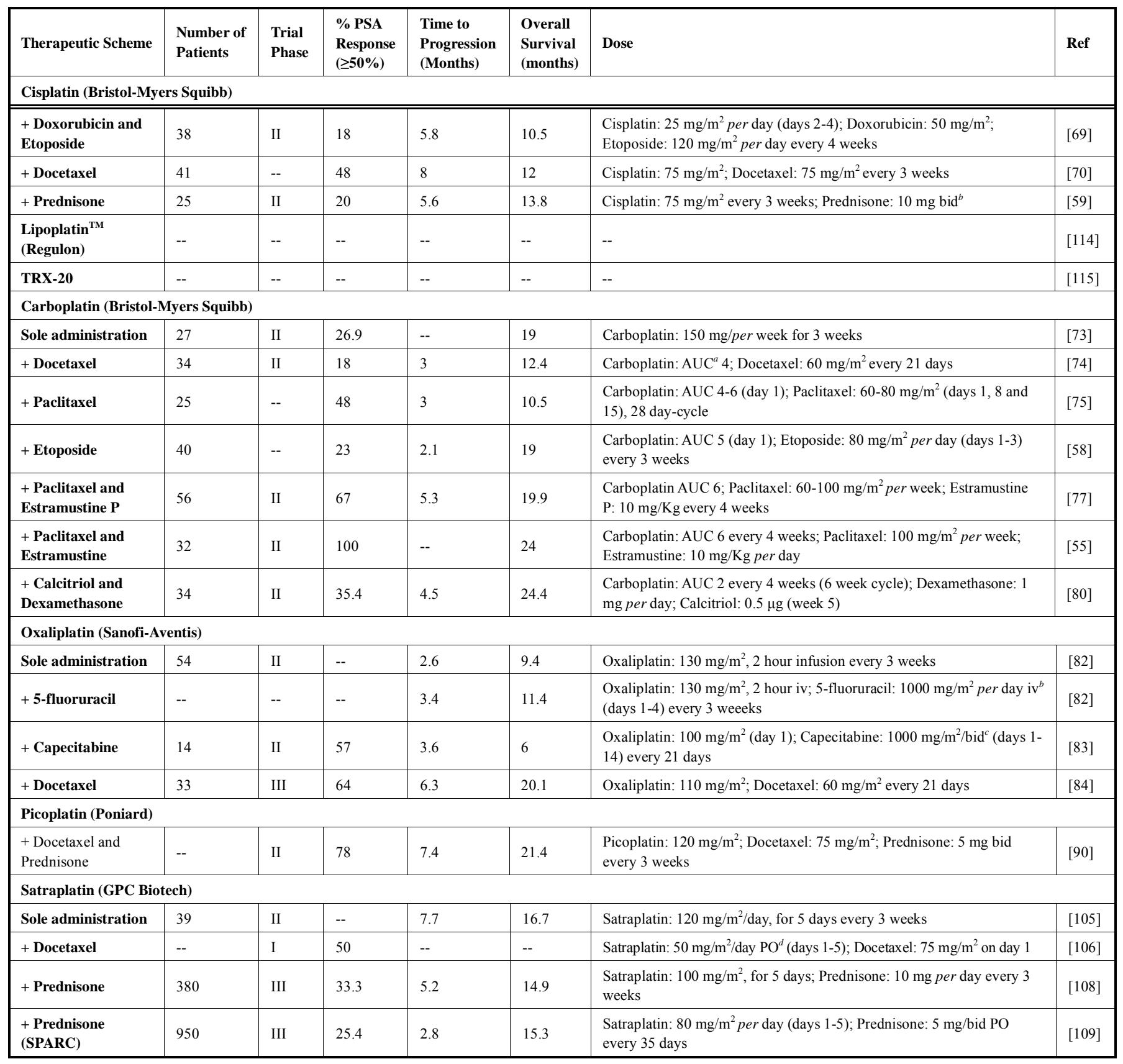

${ }^{a}$ AUC - area under the curve; ${ }^{b}$ iv - intravenous; ${ }^{c}$ bid - twice a day; ${ }^{d} \mathrm{PO}$ - orally.

Liposomal formulations of platinum agents were developed not only with a view to target the drug but also in order to reduce the systemic toxicity of this kind of compounds. Liposome-included cisplatin (Lipoplatin ${ }^{\mathrm{TM}}$ ) was found to be active against prostate cancer, through a mechanism similar to cisplatin's, with less deleterious side-effects [114]. Also, cisplatin encapsulated in polyethylene glycol-coated liposomes containing a new cationic lipid (TRX20) led to an increased delivery of the platinum agent to metastatic tumours expressing large amounts of chondroitin sulfate, such as prostate cancer [115], which constitutes a very promising approach for increasing the drug's bioavailability at its target, and hence its effectiveness.

Nanoparticles (NPs) based on biodegradable, biocompatible polymeric components, are widely applied in this field, namely NPs derived from poly(D,L-lactic-co-glycolic acid) (PLGA) as the con- trolled release polymer, which are well established as safe for clinical use [116]. Poly(ethyleneglycol) (PEG)-functionalized PLGA NPs are especially promising [117], since pegylation leads to a reduced systemic clearance of the polymeric NPs. Surface engineering methods enable to introduce tailored ligands, such as peptides, antibodies or nucleic acid aptamers, that target NPs to a cancer cell of interest. Moreover, encapsulation of the platinum drug within the cluster isolates it from the external environment diminishing deleterious side-effects and increasing blood circulation time before reaching the biological target.

Prostate specific membrane antigen (PSMA), a transmembrane glycoprotein predominantly expressed in the prostate epithelium, has been used to target prostate cancer cells. Actually, this antigen is considerably increased in these cells, particularly in poorly differentiated, prostate hormone refractory and metastatic carcinomas 
[118]. Additionally, aptamer-targeted polymeric nanoparticles have been engineered for directing platinum agents (namely cisplatin) to prostate cancer cells [119-121]. These drug-containing nanoclusters target the extracellular PSMA domain, for enhanced cytotoxicity. Moreover, this approach was found to lead to an extended drug persistence in the blood circulation and to a reduced accumulation in the kidneys, thus decreasing nephrotoxicity [121].

Platinum-based drugs have also been successfully combined with molecularly targeted drugs such as the monoclonal antibody bevacizumab (tradename Avastin), which blocks angiogenesis by inhibiting vascular endothelial growth factor and has revealed safety and efficacy in advanced prostate cancer. An encouraging therapeutic response has been obtained upon administration of carboplatin plus capecitabine in combination with bevacizumab, in patients with CRPC after failure of first-line taxane-based chemotherapy [122]. In addition, some recent studies have unveiled a synergy between platinum based chemotherapy and this immunoglobulin. In a phase II clinical trial, the combination of oral satraplatin,prednisone and bevacizumab was found to be tolerable and revealed promising efficacy in docetaxel-pretreated metastatic castrate-resistant prostate cancer patients [123].

Attending to the importance of neuroendocrine (NE) differentiation in prostate cancer, particularly in androgen-independent proliferation leading to apoptosis resistance, angiogenesis and invasion $[124,125]$, the use of chemotherapeutic agents specifically targeted to NE cells, particularly platinum drugs, may provide a novel approach or the management of CRPC [126].

\section{CONCLUSIONS}

Since hormone refractory prostate cancer causes substantial morbidity and mortality among men, improving this prognosis through the development of new chemotherapeutic regimens is an urgent issue in human health. Upon failure of androgen-deprivation treatment, several chemotherapeutic strategies have been applied, from the initial first-line estramustine (1981, [127]) and mitoxantrone plus corticosteroid [7] (1996, [128]), to docetaxel in combination with prednisone (2004, TAX 327 trial, [13]). Although the latter is the only approved therapy for metastatic hormone unresponsive prostate cancer with impact on survival, subsequent treatment options remain limited. In fact, metastatic CRPC is poorly controlled after taxane resistance, with a median survival not exceeding $c a$. 18 months, a time to progression of 3 months or less and a significant toxicity. Consequently, most patients with docetaxel-pretreated castration-resistant disease receive second-line chemotherapy, and numerous trials have been carried out in order to develop optimised regimens, regarding both efficacy and tolerabilty.

Platinum-based agents, from cisplatin and carboplatin to newer analogues including picoplatin and oxaliplatin, have shown a clinically meaningful benefit in metastatic CRPC patients, either used as single agents or in combinations. Satraplatin, in particular, has yielded very promising results, mainly in combination schemes with taxanes (e.g. docetaxel and paclitaxel) and prednisone (SPARC trial, 2003) (Table 1). Actually, the efficacy and safety findings from the SPARC trial provide evidence of patient benefit in this life-threatening disease. Moreover, satraplatin therapy offers the flexibility of an oral chemotherapeutic option (not previously available), which represents a considerable advantage regarding patient compliance, mainly in elderly men suffering from this type of cancer. Combination regimens including platinum agents and taxanes also represent a promising treatment alternative, with response rates over $50 \%$.

Although advances in palliation of symptoms and improvement in quality of life have been obtained with second-line chemotherapy, innovative approaches are still needed to improve survival rates. These include the use of targeted therapies to specific rates. These include the use of targeted therapies to specific molecular pathways or mechanisms critical to tumour growth. Several targeted delivery strategies have been developed in the last few years to widen the therapeutic use of platinum-based treatments against advanced prostate cancer. Among those, combination with specific antibodies or NP-encapsulation are promising options, leading to an effectiveness increase of up to an order of magnitude greater than that of the free drug.

Hence, patients with CRPC now have multiple options of therapy beyond conventional hormonal agents, namely tumour vaccines, combined cabazitaxel and abiraterone administration, and drugs targeting bone metastasis (often associated to advanced prostate cancer) such as the radionucleotide Alpharadin and the monoclonal antibody Denosumab. Additionally, the studies on platinum complexes towards prostate cancer developed so far have shown that this type of metal-based compounds may be of relevance, mainly as second-line therapy, for improving duration of therapeutic response and overall survival. The key for a successful development in the management of prostate cancer will require a multidisciplinary approach [129], relying on the expertise of clinicians (urologists and oncologists) as well as of basic and translational researchers, in the search for improved drug targets and the rational design of optimised drugs.

\section{CONFLICT OF INTEREST}

The author(s) confirm that this article content has no conflicts of interest.

\section{ACKNOWLEDGEMENTS}

The authors acknowledge financial support from the Portuguese Foundation for Science and Technology - PEst-OE/ QUI/ UI0070/ 2011.

\section{REFERENCES}

[1] Bryant, R.J.; Hamdy, F.C. Screening for prostate cancer: An update. Eur. Urol., 2008, 53, 37-44.

[2] Ferlay, J.; Parkin, D.M.; Steliarova-Foucher, E. Estimates of cancer incidence and mortality in Europe in 2008. Eur. J. Cancer, 2010, 46, 765781 .

[3] Oh, W.K. High-risk localized prostate cancer: integrating chemotherapy. Oncologist, 2005, 10, 18-22.

[4] Petrylak, D. Therapeutic options in androgen-independent prostate cancer: building on docetaxel. BJU Int., 2005, 96, 41-46.

[5] Sharifi, N.; Dahut, W.L.; Steinberg, S.M.; Figg, W.D.; Tarassoff, C.; Arlen, P.; Gulley, J.L. A retrospective study of the time to clinical endpoints for advanced prostate cancer. BJU Int., 2005, 96, 985-989.

[6] Aragon-Ching, J.B.; Dahut, W.L. Chemotherapy in Androgen-Independent Prostate Cancer (AIPC): What's next after taxane progression? Cancer Ther., 2007, 5, 151-160.

[7] Kantoff, P.W.; Halabi, S.; Conaway, M.; Picus, J.; Kirshner, J.; Hars, V.; Trump, D.; Winer, E.P.; Vogelzang, N.J. Hydrocortisone with or without mitoxantrone in men with hormone-refractory prostate cancer: Results of the cancer and leukemia group B 9182 study. J. Clin. Oncol., 1999, 17, 25062513.

[8] Osoba, D.; Tannock, I.F.; Ernst, D.S.; Neville, A.J. Health-related quality of life in men with metastatic prostate cancer treated with prednisone alone or mitoxantrone and prednisone. J. Clin. Oncol., 1999, 17, 1654-1663.

[9] Gulley, J.; Dahut, W.L. Chemotherapy for prostate cancer: finally an advance! Am. J. Ther., 2004, 11, 288-294.

[10] Benson, R.; Hartley-Asp, B. Mechanisms of action and clinical uses of estramustine. Cancer Invest., 1990, 8, 375-380.

[11] Petrylak, D.P.; Macarthur, R.; O'Connor, J.; Shelton, G.; Weitzman, A. Judge, T.; England-Owen, C.; Zuech, N.; Pfaff, C.; Newhouse, J.; Bagiella, E.; Hetjan, D.; Sawczuk, I.; Benson, M.; Olsson, C. Phase I/II studies of docetaxel (Taxotere) combined with estramustine in men with hormonerefractory prostate cancer. Semin. Oncol., 1999, 26, 28-33.

[12] Petrylak, D.P.; Shelton, G.B.; England-Owen, C.; Pfaff, C.; Bagliella, E.; Diuleo, R.; Katz, A.; Zuech, N.; Sawczuk, I.; Benson, M.; Olsson, C. In: Response and Preliminary Survival Results of a Phase II Study of Docetaxel $(D)+$ Estramustine $(E)$ in Patients (Pts) with AndrogenIndependent Prostate Cancer (AIPCA), Proc. Am. Soc. Clin. Oncol. 19, 2000, 334 s. 
[13] Tannock, I.F.; de Wit, R.; Berry, W.R.; Horti, J.; Pluzanska, A.; Chi, K.N.; Oudard, S.; Theodore, C.; James, N.D.; Turesson, I.; Rosenthal, M.A.; Eisenberger, M.A. Docetaxel plus prednisone or mitoxantrone plus prednisone for advanced prostate cancer. N. Engl. J. Med., 2004, 351, 1502-1512.

[14] Petrylak, D.P.; Tangen, C.M.; Hussain, M.H.; Lara, P.N., Jr.; Jones, J.A.; Taplin, M.E.; Burch, P.A.; Berry, D.; Moinpour, C.; Kohli, M.; Benson, M.C.; Small, E.J.; Raghavan, D.; Crawford, E.D. Docetaxel and estramustine compared with mitoxantrone and prednisone for advanced refractory prostate cancer. N. Engl. J. Med., 2004, 351, 1513-1520.

[15] Bradbury, J. Docetaxel with estramustine for prostate cancer. Lancet, 2007, 8,470 .

[16] Oudard, S.; Eymard, J.C.; Fizazi, K. Combining docetaxel with estramustine: back to the future? J. Clin. Oncol., 2009, 27, 1148-1149.

[17] Qi, W.X.; Shen, Z.; Yao, Y. Docetaxel-based therapy with or without estramustine as first-line chemotherapy for castration-resistant prostate cancer: a meta-analysis of four randomized controlled trials. J. Cancer Res. Clin. Oncol., 2011, 137, 1785-1790.

[18] Galsky, M.D.; Dritselis, A.; Kirkpatrick, P.; Oh, W.K. Cabazitaxel. Nat. Rev. Drug. Discov., 2010, 9, 677-678.

[19] Di Lorenzo, G.; Buonerba, C.; Autorino, R.; De Placido, S.; Sternberg, C.N. Castration-resistant prostate cancer current and emerging treatment strategies. Drugs, 2010, 70, 983-1000.

[20] De Bono, J.S.; Oudard, S.; Ozguroglu, M.; Hansen, S.; Machiels, J.-P.; Kocak, I.; Gravis, G.; Bodrogi, I.; Mackenzie, M.J.; Shen, L.; Roessner, M.; Gupta, S.; Sartor, A.O. Prednisone plus cabazitaxel or mitoxantrone for metastatic castration-resistant prostate cancer progressing after docetaxel treatment: a randomised open-label trial. Lancet, 2010, 376, 1147-1154.

[21] Harrington, J.A.; Jones, R.J. Management of metastatic castration-resistant prostate cancer after first-line docetaxel. Eur. J. Cancer, 2011, 47, 2133-2142.

[22] Kantoff, P.W.; Higano, C.S.; Shore, N.D.; Berger, E.R.; Small, E.J.; Penson, D.F.; Redfern, C.H.; Ferrari, A.C.; Dreicer, R.; Sims, R.B.; Xu, Y.; Frohlich, M.W.; Schellhammer, P.F. Sipuleucel-T immunotherapy for castrationresistant prostate cancer. N. Engl. J. Med., 2010, 363, 411-422.

[23] Joniau, S.; Abrahamsson, P.A.; Bellmunt, J.; Figdor, C.; Hamdy, F.; Verhagen, P.; Vogelzang, N.J.; Wirth, M.; Van Poppel, H.; Osanto, S. Current vaccination strategies for prostate cancer. Eur. Urol., 2012, 61, 290-306.

[24] Shore, N.; Mason, M.; de Reijke, T.M. New developments in castrateresistant prostate cancer. BJU Int., 2012, 109 Suppl 6, 22-32.

[25] Parker, C.; Heinrich, D.; O'Sullivan, J.M.; Fosså, S.; Chodacki, A.; Demkow, T.; Cross, A.; O'Bryan-Tear, C.G.; Garcia-Vargas, J.; Sartor, O. In: Overall survival benefit of radium-223 chloride (Alpharadin) in the treatment of patients with symptomatic bone metastasis in castration-resistant prostate cancer: a phase III randomised trial, ECCO-ESMO Annual Congress, 2011.

[26] Smith, M.R.; Egerdie, B.; Hernandez Toriz, N.; Feldman, R.; Tammela, T.L.; Saad, F.; Heracek, J.; Szwedowski, M.; Ke, C.; Kupic, A.; Leder, B.Z.; Goessl, C. Denosumab in men receiving androgen-deprivation therapy for prostate cancer. N. Engl. J. Med., 2009, 361, 745-755.

[27] Helo, S.; Manger, J.P.; Krupski, T.L. Role of denosumab in prostate cancer. Prostate Cancer Prostatic Dis., 2012, ahead of print.

[28] Fizazi, K.; Carducci, M.; Smith, M.; Damião, R.; Brown, J.; Karsh, L.; Milecki, P.; Shore, N.; Rader, M.; Wang, H.; Jiang, Q.; Tadros, S.; Dansey, R.; Goessl, C. Denosumab versus zoledronic acid for treatment of bone metastases in men with castration-resistant prostate cancer: a randomised, double-blind study. Lancet, 2011, 377, 813-822.

[29] Smith, M.R.; Saad, F.; Coleman, R.; Shore, N.; Fizazi, K.; Tombal, B.; Miller, K.; Sieber, P.; Karsh, L.; Damiao, R.; Tammela, T.L.; Egerdie, B.; Van Poppel, H.; Chin, J.; Morote, J.; Gomez-Veiga, F.; Borkowski, T.; Ye, Z.; Kupic, A.; Dansey, R.; Goessl, C. Denosumab and bone-metastasis-free survival in men with castration-resistant prostate cancer: results of a phase 3 , randomised, placebo-controlled trial. Lancet, 2012, 379, 39-46.

[30] Tran, C.; Ouk, S.; Clegg, N.J.; Chen, Y.; Watson, P.A.; Arora, V.; Wongvipat, J.; Smith-Jones, P.M.; Yoo, D.; Kwon, A.; Wasielewska, T.; Welsbie, D.; Chen, C.D.; Higano, C.S.; Beer, T.M.; Hung, D.T.; Scher, H.I.; Jung, M.E.; Sawyers, C.L. Development of a second-generation antiandrogen for treatment of advanced prostate cancer. Science, 2009, 324, 787-790.

[31] Jung, M.E.; Ouk, S.; Yoo, D.; Sawyers, C.L.; Chen, C.; Tran, C.; Wongvipat, J. Structure-activity relationship for thiohydantoin androgen receptor antagonists for castration-resistant prostate cancer (CRPC). J. Med. Chem., 2010, 53, 2779-2796.

[32] Scher, H.I.; Beer, T.M.; Higano, C.S.; Anand, A.; Taplin, M.E.; Efstathiou, E.; Rathkopf, D.; Shelkey, J.; Yu, E.Y.; Alumkal, J.; Hung, D.; Hirmand, M.; Seely, L.; Morris, M.J.; Danila, D.C.; Humm, J.; Larson, S.; Fleisher, M.; Sawyers, C.L. Antitumour activity of MDV3100 in castration-resistant prostate cancer: a phase 1-2 study. Lancet, 2010, 375, 1437-1446.

[33] Ang, J.E.; Olmos, D.; de Bono, J.S. CYP17 blockade by abiraterone: further evidence for frequent continued hormone-dependence in castration-resistant prostate cancer. Brit. J. Cancer, 2009, 100, 671-675.

[34] de Bono, J.S.; Logothetis, C.J.; Molina, A.; Fizazi, K.; North, S.; Chu, L.; Chi, K.N.; Jones, R.J.; Goodman, O.B., Jr.; Saad, F.; Staffurth, J.N.; Mainwaring, P.; Harland, S.; Flaig, T.W.; Hutson, T.E.; Cheng, T.; Patterson, H.; Hainsworth, J.D.; Ryan, C.J.; Sternberg, C.N.; Ellard, S.L.; Flechon, A.; Saleh, M.; Scholz, M.; Efstathiou, E.; Zivi, A.; Bianchini, D.; Loriot, Y.; Chieffo, N.; Kheoh, T.; Haqq, C.M.; Scher, H.I. Abiraterone and increased survival in metastatic prostate cancer. N. Engl. J. Med., 2011, 364, 19952005 .
[35] Pezaro, C.J.; Mukherji, D.; De Bono, J.S. Abiraterone acetate: redefining hormone treatment for advanced prostate cancer. Drug Discov. Today, 2012, 17, 221-226.

[36] Pal, S.K.; Sartor, O. Phase III data for abiraterone in an evolving landscape for castration-resistant prostate cancer. Maturitas, 2011, 68, 103-105.

[37] Beuzeboc, P.; Ropert, S.; Goldwasser, F.; Zerbib, M. Management of metastatic castration-resistant prostate cancer following docetaxel. Bull. Cancer, 2012.

[38] Colloca, G.; Venturino, A.; Checcaglini, F. Second-line chemotherapy in metastatic docetaxel-resistant prostate cancer: a review. Med. Oncol., 2011, $1-10$.

[39] Ohlmann, C.H.; Merseburger, A.S.; Suttmann, H.; Schilling, D.; Trojan, L.; Kempkensteffen, C.; Corvin, S.; Mathers, M.J.; Bastian, P.J. Novel options for the treatment of castration-resistant prostate cancer. World J. Urol., 2011, $1-9$.

[40] Gilligan, T.; Kantoff, P.W. Chemotherapy for prostate cancer. Urology, 2002, 60, 94-100.

[41] Goodin, S.; Rao, K.V.; DiPaola, R.S. State-of-the-art treatment of metastatic hormone-refractory prostate cancer. Oncologist, 2002, 7, 360-370.

[42] McKeage, M.J. New-generation platinum drugs in the treatment of cisplatinresistant cancers. Expert Opin. Investig. Drugs, 2005, 14, 1033-1046.

[43] Attard, G.; Sarker, D.; Reid, A.; Molife, R.; Parker, C.; de Bono, J.S Improving the outcome of patients with castration-resistant prostate cancer through rational drug development. Brit. J. Cancer, 2006, 95, 767-774.

[44] Haines, I.E.; Stanley, R.M. Perspective on "Chemotherapy for Advanced Prostate Cancer: 25 Years Later": Is it a mirage or an oasis? J. Clin. Oncol., 2008, 26, 4049-4050.

[45] Nelius, T.; Filleur, S. PSA surge/flare-up in patients with castrationrefractory prostate cancer during the initial phase of chemotherapy. Prostate, 2009, 69, 1802-1807

[46] Kostova, I. Platinum complexes as anticancer agents. Recent Pat. Anticancer Drug Discov., 2006, 1, 1-22.

[47] Farrell, N.P. Platinum formulations as anticancer drugs clinical and preclinical studies. Curr. Top. Med. Chem., 2011, 11, 2623-2631.

[48] Carducci, M.A.; DeWeese, T.L.; Nelson, J.B. Prostate-specific antigen and other markers of therapeutic response. Urol. Clin. North Am., 1999, 26, 291302.

[49] Oh, W.K.; Tay, M.H.; Huang, J.T. Is there a role for platinum chemotherapy in the treatment of patients with hormone-refractory prostate cancer? Cancer, 2007, 109, 477-486.

[50] Shah, N.; Dizon, D.S. New-generation platinum agents for solid tumors. Future Oncol., 2009, 5, 33-42.

[51] Brick, A.; Niu, J.; Huang, J.; Oh, W.K. Figg, W.D.; Chau, C.H.; Small, E.J., Eds.; Springer New York, 2010, pp 153-161.

[52] Oh, W.K.; Halabi, S.; Kelly, W.K.; Werner, C.; Godley, P.A.; Vogelzang, N.J.; Small, E.J.; B, C.L.G. A phase II study of estramustine, docetaxel, and carboplatin with granulocyte-colony-stimulating factor support in patients with hormone-refractory prostate carcinoma - Cancer and leukemia group B 99813. Cancer, 2003, 98, 2592-2598.

[53] Oh, W.K.; Hagmann, E.; Manola, J.; George, D.J.; Gilligan, T.D.; Jacobson, J.O.; Smith, M.R.; Kaufman, D.S.; Kantoff, P.W. A phase I study of estramustine, weekly docetaxel, and carboplatin chemotherapy in patients with hormone-refractory prostate cancer. Clin. Cancer Res., 2005, 11, 284289.

[54] Canobbio, L.; Guarneri, D.; Miglietta, L.; Decensi, A.; Oneto, F.; Boccardo, F. Carboplatin in Advanced Hormone-Refractory Prostatic-Cancer Patients. Eur. J. Cancer, 1993, 29A, 2094-2096.

[55] Urakami, S.; Igawa, M.; Kikuno, N.; Yoshino, T.; Kishi, H.; Shigeno, K.; Shiina, H. Combination chemotherapy with paclitaxel, estramustine and carboplatin for hormone refractory prostate cancer. J. Urology, 2002, 168, 2444-2450.

[56] Solit, D.B.; Morris, M.; Slovin, S.; Curley, T.; Schwartz, L.; Larson, S ; Kattan, M.W.; Hartley-Asp, B.; Scher, H.I.; Kelly, W.K. Clinical experience with intravenous estramustine phosphate, paclitaxel, and carboplatin in patients with castrate, metastatic prostate adenocarcinoma. Cancer, 2003, 98, 1842-1848.

[57] Regan, M.M.; O'Donnell, E.K.; Kelly, W.K.; Halabi, S.; Berry, W.; Urakami, S.; Kikuno, N.; Oh, W.K. Efficacy of carboplatin-taxane combinations in the management of castration-resistant prostate cancer: a pooled analysis of seven prospective clinical trials. Ann. Oncol., 2010, 21, 312-318.

[58] Loriot, Y.; Massard, C.; Gross-Goupil, M.; Di Palma, M.; Escudier, B.; Bossi, A.; Fizazi, K. Combining carboplatin and etoposide in docetaxel-pretreated patients with castration-resistant prostate cancer: a prospective study evaluating also neuroendocrine features. Ann. Oncol., 2009, 20, 703-708.

[59] Buonerba, C.; Federico, P.; D'Aniello, C.; Rescigno, P.; Cavaliere, C.; Puglia, L.; Ferro, M.; Altieri, V.; Perdona, S.; De Placido, S.; Lorenzo, G. Phase II trial of cisplatin plus prednisone in docetaxel-refractory castrationresistant prostate cancer patients. Cancer Chemother. Pharmcol., 2011, 67, 1455-1461.

[60] Rosenberg, B.; Vancamp, L.; Krigas, T. Inhibition of Cell Division in Escherichia Coli by Electrolysis Products from a Platinum Electrode. Nature, 1965, 205, 698-699.

[61] Rosenberg, B.; Vancamp, L.; Trosko, J.E.; Mansour, V.H. Platinum Compounds - a New Class of Potent Antitumour Agents. Nature, 1969, 222, 385-386. 
[62] Wang, D.; Lippard, S.J. Cellular processing of platinum anticancer drugs. Nat. Rev. Drug. Discov., 2005, 4, 307-320.

[63] Rosenberg, J.E.; Weinberg, V.K.; Kelly, W.K.; Michaelson, D.; Hussain, M.H.; Wilding, G.; Gross, M.; Hutcheon, D.; Small, E.J. Activity of secondline chemotherapy in docetaxel-refractory hormone-refractory prostate cancer patients - Randomized phase 2 study of ixabepilone or mitoxantrone and prednisone. Cancer, 2007, 110, 556-563.

[64] Komeda, S. Unique platinum-DNA interactions may lead to more effective platinum-based antitumor drugs. Metallomics, 2011, 3, 650-655.

[65] Rossof, A.H.; Talley, R.W.; Stephens, R.; Thigpen, T.; Samson, M.K.; Groppe, C., Jr.; Eyre, H.J.; Fisher, R. Phase II evaluation of cisdichlorodiammineplatinum(II) in advanced malignancies of the genitourinary and gynecologic organs: a Southwest Oncology Group Study. Cancer Treat. Rep., 1979, 63, 1557-1564.

[66] Merrin, C.E. Treatment of Previously Untreated (by Hormonal Manipulation) Stage-D Adenocarcinoma of Prostate with Combined Orchiectomy, Estrogen, and Cis Diamminedichloroplatinum. Urology, 1980, $15,123-126$.

[67] Moore, M.R.; Troner, M.B.; Desimone, P.; Birch, R.; Irwin, L. Phase-Ii Evaluation of Weekly Cisplatin in Metastatic Hormone-Resistant ProstateCancer - a Southeastern Cancer Study-Group Trial. Cancer Treat. Rep., 1986, 70, 541-542

[68] Yagoda, A. Phase-Ii Trials with Cis-Dichlorodiammineplatinum(Ii) in the Treatment of Urothelial Cancer. Cancer Treat. Rep., 1979, 63, 1565-1572.

[69] Papandreou, C.N.; Daliani, D.D.; Thall, P.F.; Tu, S.M.; Wang, X.M.; Reyes, A.; Troncoso, P.; Logothetis, C.J. Results of a phase II study with doxorubicin, etoposide, and cisplatin in patients with fully characterized small-cell carcinoma of the prostate. J. Clin. Oncol., 2002, 20, 3072-3080.

[70] Culine, S.; El Demery, M.; Lamy, P.J.; Iborra, F.; Avances, C.; Pinguet, F. Docetaxel and cisplatin in patients with metastatic androgen independent prostate cancer and circulating neuroendocrine markers. J. Urology, 2007, $178,844-848$.

[71] Hah, S.S.; Stivers, K.M.; White, R.W.D.; Henderson, P.T. Kinetics of carboplatin-DNA binding in genomic DNA and bladder cancer cells as determined by accelerator mass spectrometry. Chem. Res. Toxicol., 2006, 19, 622-626.

[72] Fricker, S.P. Metal based drugs: from serendipity to design. Dalton Trans., 2007, 4903-4917.

[73] Castagneto, B.; Ferraris, V.; Perachino, M. In: Weekly administration of standardized low-disk carboplatin (CBDCA) in the treatment of advanced hormone-refractory prostate cancer (HRPC): a phase II study, Proceedings ASCO Prostate Symposium, 2006.

[74] Ross, R.W.; Beer, T.M.; Jacobus, S.; Bubley, G.J.; Taplin, M.E.; Ryan, C.W.; Huang, J.; Oh, W.K.; Conso, P.C.C.T. A phase 2 study of carboplatin plus docetaxel in men with metastatic hormone-refractory prostate cancer who are refractory to docetaxel. Cancer, 2008, 112, 521-526.

[75] Jeske, S.; Tagawa, S.T.; Olowokure, O.; Selzer, J.; Giannakakou, P.; Nanus, D.M. Carboplatin plus paclitaxel therapy after docetaxel in men with metastatic castrate resistant prostate cancer. Urol. Oncol., 2011, 29, 676-681.

[76] Hande, K.R. Etoposide: four decades of development of a topoisomerase II inhibitor. Eur. J. Cancer, 1998, 34, 1514-1521.

[77] Kelly, W.K.; Curley, T.; Slovin, S.; Heller, G.; McCaffrey, J.; Bajorin, D.; Ciolino, A.; Regan, K.; Schwartz, M.; Kantoff, P.; George, D.; Oh, W.; Smith, M.; Kaufman, D.; Small, E.J.; Schwartz, L.; Larson, S.; Tong, W.; Scher, H. Paclitaxel, estramustine phosphate, and carboplatin in patients with advanced prostate cancer. J. Clin. Oncol., 2001, 19, 44-53.

[78] Kikuno, N.; Urakami, S.; Nakamura, S.; Hiraoka, T.; Hyuga, T.; Arichi, N.; Wake, K.; Sumura, M.; Yoneda, T.; Kishi, H.; Shigeno, K.; Shiina, H.; Igawa, M. Phase-II study of docetaxel, estramustine phosphate, and carboplatin in patients with hormone-refractory prostate cancer. Eur. Urol., 2007, 51, 1252-1258.

[79] Berry, W.; Friedland, D.; Fleagle, J.; Jackson, D.; Ilegbodu, D.; Boehm, K.A.; Asmar, L. A phase II study of weekly paclitaxel/ estramustine/ carboplatin in hormone-refractory prostate cancer. Clin. Genitourin. Cancer, 2006, 5, 131-137.

[80] Flaig, T.W.; Barqawi, A.; Miller, G.; Kane, M.; Zeng, C.; Crawford, E.D.; Glode, L.M. A phase II trial of dexamethasone, vitamin D, and carboplatin in patients with hormone-refractory prostate cancer. Cancer, 2006, 107, 266-274.

[81] Raymond, E.; Faivre, S.; Chaney, S.; Woynarowski, J.; Cvitkovic, E. Cellular and molecular pharmacology of oxaliplatin. Mol. Cancer Ther., 2002, 1, 227-235.

[82] Droz, J.P.; Muracciole, X.; Mottet, N.; Kaci, M.O.; Vannetzel, J.M.; Albin, N.; Culine, S.; Rodier, J.M.; Misset, J.L.; Mackenzie, S.; Cvitkovic, E.; Benoit, G. Phase II study of oxaliplatin versus oxaliplatin combined with infusional 5-fluorouracil in hormone refractory metastatic prostate cancer patients. Ann. Oncol., 2003, 14, 1291-1298.

[83] Blesa, J.M.G.; Marco, V.G.; Giner-Bosch, V.; Fuentes, P.C.; Candel, V.A. Phase II Trial of Oxaliplatin and Capecitabine After Progression to First-Line Chemotherapy in Androgen-Independent Prostate Cancer Patients. Am. J. Clin. Oncol., 2011, 34, 155-159.

[84] Chatta, G.S.; Feinstein, T.M.; Appleman, L.J.; Friedland, D.M.; Jacobs, S.A.; Evans, T.L.; Earle, M.F.; Strausser, H.M.; Gooding, W.E.; Lenzner, D. In: Oxaliplatin and docetaxel in castration-resistant prostate cancer (CRPC) patients treated with up to two prior chemotherapeutic regimens: Updated results of a phase II trial, J. Clin. Oncol. 26, 2008.
[85] Holford, J.; Raynaud, F.; Murrer, B.A.; Grimaldi, K.; Hartley, J.A.; Abrams, M.; Kelland, L.R. Chemical, biochemical and pharmacological activity of the novel sterically hindered platinum co-ordination complex, cis[amminedichloro(2-methylpyridine)] platinum(II) (AMD473). Anticancer Drug Des., 1998, 13, 1-18.

[86] Holford, J.; Sharp, S.Y.; Murrer, B.A.; Abrams, M.; Kelland, L.R. In vitro circumvention of cisplatin resistance by the novel sterically hindered platinum complex AMD473. Brit. J. Cancer, 1998, 77, 366-373.

[87] Gelmon, K.A.; Stewart, D.; Chi, K.N.; Chia, S.; Cripps, C.; Huan, S.; Janke, S.; Ayers, D.; Fry, D.; Shabbits, J.A.; Walsh, W.; McIntosh, L.; Seymour, L.K. A phase I study of AMD473 and docetaxel given once every 3 weeks in patients with advanced refractory cancer: a National Cancer Institute of Canada-Clinical Trials Group trial, IND 131. Ann. Oncol., 2004, 15, 11151122.

[88] Kelland, L. Broadening the clinical use of platinum drug-based chemotherapy with new analogues: satraplatin and picoplatin. Expert Opin. Investig. Drugs, 2007, 16, 1009-1021.

[89] Chen, Y.; Guo, Z.J.; Parsons, S.; Sadler, P.J. Stereospecific and kinetic control over the hydrolysis of a sterically hindered platinum picoline anticancer complex. Chem. Eur. J., 1998, 4, 672-676.

[90] De Jager, R.L.; Roman, L.; Lopatkin, N.; Karlov, P.; Breitz, H.; Earhart, R. Results of a phase II study of picoplatin with docetaxel and prednisone in first-line treatment of castration-resistant prostate cancer (CRPC). J. Clin. Oncol., 2009, 27.

[91] Breitz, H.B.; Roman, L.A.; Karlov, P.A.; Cheporov, S.V.; Lopatkin, N.D.; Baker, G.S.; Karlin, D.A. In: A phase II study of picoplatin with docetaxel and prednisone in chemotherapy-naïve patients with metastatic hormone refractory prostate cancer (HRPC), J.Clin.Oncol. 26, 2008, 5153.

[92] Bhargava, A.; Vaishampayan, U.N. Satraplatin: leading the new generation of oral platinum agents. Expert Opin. Investig. Drugs, 2009, 18, 1787-1797.

[93] Choy, H.; Park, C.; Yao, M. Current status and future prospects for satraplatin, an oral platinum analogue. Clin. Cancer Res., 2008, 14, 16331638 .

[94] Kelland, L.R. An update on satraplatin: the first orally available platinum anticancer drug. Expert Opin. Investig. Drugs, 2000, 9, 1373-1382.

[95] Kelland, L. The resurgence of platinum-based cancer chemotherapy. Nat. Rev. Cancer, 2007, 7, 573-584.

[96] Fokkema, E.; Groen, H.J.M.; Helder, M.N.; de Vries, E.G.E.; Meijer, C JM216-, JM118-, and cisplatin-induced cytotoxicity in relation to platinumDNA adduct formation, glutathione levels and p53 status in human tumour cell lines with different sensitivities to cisplatin. Biochem. Pharmacol., 2002, 63, 1989-1996.

[97] Sessa, C.; Minoia, C.; Ronchi, A.; Zucchetti, M.; Bauer, J.; Borner, M.; de Jong, J.; Pagani, O.; Renard, J.; Weil, C.; D'lncalci, M. Phase I clinical and pharmacokinetic study of the oral platinum analogue JM216 given daily for 14 days. Ann. Oncol., 1998, 9, 1315-1322.

[98] Kalimutho, M.; Minutolo, A.; Grelli, S.; Formosa, A.; Sancesario, G.; Valentini, A.; Federici, G.; Bernardini, S. Satraplatin (JM-216) mediates G2/M cell cycle arrest and potentiates apoptosis via multiple death pathways in colorectal cancer cells thus overcoming platinum chemo-resistance. Cancer Chemother. Pharmcol., 2011, 67, 1299-1312.

[99] Mckeage, M.J.; Mistry, P.; Ward, J.; Boxall, F.E.; Loh, S.; Oneill, C.; Ellis, P.; Kelland, L.R.; Morgan, S.E.; Murrer, B.; Santabarbara, P.; Harrap, K.R.; Judson, I.R. A Phase-I and Pharmacology Study of an Oral Platinum Complex, Jm216 - Dose-Dependent Pharmacokinetics with Single-Dose Administration. Cancer Chemother. Pharmcol., 1995, 36, 451-458.

[100] McKeage, M.J.; Raynaud, F.; Ward, J.; Berry, C.; ODell, D.; Kelland, L.R.; Murrer, B.; Santabarabara, P.; Harrap, K.R.; Judson, I.R. Phase I and pharmacokinetic study of an oral platinum complex given daily for 5 days in patients with cancer. J. Clin. Oncol., 1997, 15, 2691-2700.

[101] McKeage, M.J.; Kelland, L.R.; Boxall, F.E.; Valenti, M.R.; Jones, M.; Goddard, P.M.; Gwynne, J.; Harrap, K.R. Schedule dependency of orally administered bis-acetato-ammine-dichloro-cyclohexylamine-platinum(IV) (JM216) in vivo. Cancer Res., 1994, 54, 4118-4122.

[102] Wosikowski, K.; Lamphere, L.; Unteregger, G.; Jung, V.; Kaplan, F.; Xu, J.P.; Rattel, B.; Caligiuri, M. Preclinical antitumor activity of the oral platinum analog satraplatin. Cancer Chemother. Pharmcol., 2007, 60, 589600.

[103] Beale, P.; Raynaud, F.; Hanwell, J.; Berry, C.; Moore, S.; Odell, D.; Judson, I. Phase I study of oral JM216 given twice daily. Cancer Chemother. Pharmcol., 1998, 42, 142-148.

[104] Kurata, T.; Tamura, T.; Sasaki, Y.; Fujii, H.; Negoro, S.; Fukuoka, M.; Saijo, $\mathrm{N}$. Pharmacokinetic and pharmacodynamic analysis of bis-acetato-amminedichloro-cyclohexylamine-platinum(IV) (JM216) administered once a day for five consecutive days: a phase I study. Jpn. J. Clin. Oncol., 2000, 30 , 377-384.

[105] Latif, T.; Wood, L.; Connell, C.; Smith, D.C.; Vaughn, D.; Lebwohl, D.; Peereboom, D. Phase II study of oral bis (aceto) ammine dichloro (cyclohexamine) platinum (IV) (JM-216, BMS-182751) given daily x 5 in hormone refractory prostate cancer (HRPC). Invest. New Drugs, 2005, 23 , 79-84.

[106] Cetnar, J.; Wilding, G.; McNeel, D.; Loconte, N.K.; McFarland, T.A.; Eickhoff, J.; Liu, G. A phase 1/1b study of satraplatin (JM-216) in combination with docetaxel in patients with advanced solid tumors and metastatic castrate-resistant prostate cancer. Urol. Oncol., 2011, 1-6. 
[107] Beltran, H.; Beer, T.M.; Carducci, M.A.; de Bono, J.; Gleave, M.; Hussain, M.; Kelly, W.K.; Saad, F.; Sternberg, C.; Tagawa, S.T.; Tannock, I.F. New therapies for castration-resistant prostate cancer: efficacy and safety. Eur. Urol., 2011, 60, 279-290.

[108] Sternberg, C.N.; Whelan, P.; Hetherington, J.; Paluchowska, B.; Slee, P.H.T.J.; Vekemans, K.; Van Erps, P.; Theodore, C.; Koriakine, O.; Oliver, T.; Lebwohl, D.; Debois, M.; Zurlo, A.; Collette, L.; EORTC, G.T.G. Phase III trial of satraplatin, an oral platinum plus prednisone vs. prednisone alone in patients with hormone-refractory prostate cancer. Oncology, 2005, 68, 2-9.

[109] Sternberg, C.N.; Petrylak, D.P.; Sartor, O.; Witjes, J.A.; Demkow, T.; Ferrero, J.M.; Eymard, J.C.; Falcon, S.; Calabro, F.; James, N.; Bodrogi, I.; Harper, P.; Wirth, M.; Berry, W.; Petrone, M.E.; McKearn, T.J.; Noursalehi, M.; George, M.; Rozencweig, M. Multinational, Double-Blind, Phase III Study of Prednisone and Either Satraplatin or Placebo in Patients With Castrate-Refractory Prostate Cancer Progressing After Prior Chemotherapy: The SPARC Trial. J. Clin. Oncol., 2009, 27, 5431-5438.

[110] Petrylak, D.P.; Sartor, O.; Witjes, J.; Ferrero, J.; Berry, W.R.; Koletsky, A.; Lacon, S.; Nathan, F.E.; Petrone, M.E.; Sternberg, C. In: A phase III, randomized, double-blind trial of satraplatin and prednisone vs placebo and prednisone for patients with hormone refractory prostate cancer (HRPC), Prostate Cancer Symposium, 2007.

[111] Langer, R. Perspectives: Drug delivery - Drugs on target. Science, 2001, 293 , 58-59.

[112] van Zutphen, S.; Reedijk, J. Targeting platinum anti-tumour drugs: Overview of strategies employed to reduce systemic toxicity. Coordin. Chem. Rev., 2005, 249, 2845-2853.

[113] Haxton, K.J.; Burt, H.M. Polymeric Drug Delivery of Platinum-Based Anticancer Agents. J. Pharm. Sci., 2009, 98, 2299-2316.

[114] Boulikas, T. Low toxicity and anticancer activity of a novel liposomal cisplatin (lipoplatin) in mouse xenografts. Oncol. Rep., 2004, 12, 3-12.

[115] Lee, C.M.; Tanaka, T.; Murai, T.; Kondo, M.; Kimura, J.; Su, W.; Kitagawa, T.; Ito, T.; Matsuda, H.; Miyasaka, M. Novel chondroitin sulfate-binding cationic liposomes loaded with cisplatin efficiently suppress the local growth and liver metastasis of tumor cells in vivo. Cancer Res., 2002, 62, 42824288

[116] Langer, R. Drug delivery and targeting. Nature, 1998, 392, 5-10.

[117] Gryparis, E.C.; Hatziapostolou, M.; Papadimitriou, E.; Avgoustakis, K. Anticancer activity of cisplatin-loaded PLGA-mPEG nanoparticles on LNCaP prostate cancer cells. Eur. J. Pharm. Biopharm., 2007, 67, 1-8.
[118] Fu, W; Madan, E. Yee, M. Zhang, H. Progress of molecular targeted therapies for prostate cancers. Biochim. Biophys. Acta, 2012, 1825, 140-152.

[119] Farokhzad, O.C.; Jon, S.; Khademhosseini, A.; Tran, T.N.; Lavan, D.A.

Langer, R. Nanoparticle-aptamer bioconjugates: a new approach for targeting prostate cancer cells. Cancer Res., 2004, 64, 7668-7672.

[120] Dhar, S.; Gu, F.X.; Langer, R.; Farokhzad, O.C.; Lippard, S.J. Targeted delivery of cisplatin to prostate cancer cells by aptamer functionalized $\mathrm{Pt}(\mathrm{IV})$ prodrug-PLGA-PEG nanoparticles. Proc. Natl. Acad. Sci. USA, 2008, 105 , 17356-17361.

[121] Dhar, S.; Kolishetti, N.; Lippard, S.J.; Farokhzad, O.C. Targeted delivery of a cisplatin prodrug for safer and more effective prostate cancer therapy in vivo. Proc. Natl. Acad. Sci. USA, 2011, 108, 1850-1855.

[122] Wu, S.; Madajewicz, S. In: Durable response to the combination of carboplatin/capecitabine with bevacizumab in a patient with metastatic hormone- refractory prostate cancer resistant to docetaxel-based chemotherapy, Prostate Cancer Symposium, 2007.

[123] Vaishampayan, U.N.; Heilbrun, L.K.; Dickow, B.; Heath, E.I.; Smith, D.W Baranowski, K.; Cher, M.L.; Powell, I.; Pontes, J.E.; Fontana, J.A. In: Phase II trial of combination therapy with intravenous bevacizumab $(B)$, oral satraplatin $(S)$, and prednisone $(P)$ in docetaxel-pretreated $(D P)$ metastatic castrate-resistant prostate cancer (CRPC), J.Clin.Oncol. 29(S7) 2011.

[124] Sun, Y.; Niu, J.; Huang, J. Neuroendocrine differentiation in prostate cancer Am J Transl Res, 2009, 1, 148-162.

[125] Alberti, C. Neuroendocrine differentiation in prostate carcinoma: focusing on its pathophysiologic mechanisms and pathological features. G. Chir., 2010, $31,568-574$

[126] Sciarra, A.; Innocenzi, M.; Ravaziol, M.; Minisola, F.; Alfarone, A Cattarino, S.; Monti, G.; Gentile, V.; Di Silverio, F. Neuroendocrine target therapies for prostate cancer. Urologia, 2011, 78, 137-141

[127] Edsmyr, F.; Esposti, P.L.; Johansson, B.; Strindberg, B. Clinical experimental randomized trial of 2,6-cis-diphenyl hexamethyl cyclo tetrasiloxane and estramustine-17- phosphate in the treatment of prostatic carcinoma. J. Urology, 1978, 120, 705-707.

[128] Tannock, I.F.; Osoba, D.; Stockler, M.R.; Ernst, D.S.; Neville, A.J.; Moore, M.J.; Armitage, G.R.; Wilson, J.J.; Venner, P.M.; Coppin, C.M.L.; Murphy, K.C. Chemotherapy with mitoxantrone plus prednisone or prednisone alone for symptomatic hormone-resistant prostate cancer: A Canadian randomized trial with palliative end points. J. Clin. Oncol., 1996, 14, 1756-1764.

[129] Montagut, C.; Albanell, J.; Bellmunt, J. Prostate cancer Multidisciplinary approach: a key to success. Crit. Rev. Oncol. Hemat., 2008, 68, S32-S36. 